\title{
THE EARTHWORM AND THE METHOD OF TRIAL
}

\author{
L. H. BITTNER, G. R. JOHNSON, AND H. B. TORREY \\ Reed College, Portland, Oregon
}

About ten years ago Jennings attempted to clarify existing conceptions of the behavior of the lower organisms by substituting for what he believed to be an inadequate theory of tropisms a conception that rested on what has come to be known as the "method of trial."

Tropism hypotheses have existed at various times that have differed in various respects. There is no doubt that in one respect or another, some of these hypotheses have been open to just criticism. That the method of trial affords an escape from such criticism, however, is becoming less and less apparent with the passage of time.

Notwithstanding their differences, all tropism hypotheses agree in excluding the conception of orientation by trial reactions. Fundamental to them all is the conception of orientation by means of movements that, with reference to a given source of stimulation, are predictablc as to direction. However cogent, then, the criticism of a particular variety of tropism hypothesis in other respects, it can hardly affect the fundamental characteristic which they all possess in common.

Some months ago, an analysis of the behavior of Porcellio scaber showed that the method of trial was incompetent to interpret the orientation of this organism under photic stimulation. ${ }^{1}$ In the present paper we shall consider the orientation, under similar stimulation, of the earthworm (Allolobophora sp.), an organism of some complexity of structure, whose behavior has seemed to some observers to lend support to the method of trial. These critics have based their conclusions in part on observations," in part on the identification of "random" with

1 Torrey and Hays. The Role of Random Movements in the Orientation of Porcellio scaber to Light. Jour. Animal Behav., 1914, 4, p. 110.

${ }_{2}^{2}$ See especially Holmes. The Selection of Random Movements as a Factor in Phototaxis. Jour. Comp. Neur. Psych., 1905, 15, p. 98. 
"trial" movements, a source of confusion that has already been discussed in the paper on Porcellio to which we have just referred.

The earthworm comes midway between the sow bug (Porcellio) and the leech in the freedom with which it bends its body when reacting to light. It has been shown ${ }^{3}$ that the first movements of Porcellio after stimulation are away from the source of light. The body moves stiffly as a whole. The photoreceptors are anteriorly placed paired eyes. Holmes cites observations on the leech Glossosiphonia that show a wide range of mobility in its response to light, dependent upon its characteristic locomotion. The earthworm does not react stiffly, like Porcellio, nor are more than a very few anterior segments concerned in whatever random movements may be observable under photic stimulation. Holmes was led to believe that the method or orientation of the leech is, in principle, the same as that of the earthworm. He calls especial attention to the characteristic waving of the body, preliminary to fixation of the anterior end. Our observations, however, encourage us to place emphasis on the resemblance of the reactions of the earthworm to the behavior rather of Porcellio than of Glossosiphonia. The random movements of the earthworm have thus appeared to us to be less significant elements in its orientation to light than the observations of Holmes indicated.

It is characteristic of the earthworm when advancing in diffused light, to protrude its anterior end first on one side and then on the other, with successive extensions, in fairly regular alternation. A distinct tendency thus exists for this end, when bent to one side, to bend to the opposite side at the next extension. Mechanical causes, such as tensions in muscles and skin, are probably responsible for it. It is natural to expect evidence of this tendency in experiments on earthworms where relatively low intensities of light are employed unilaterally. Mast, indeed, asserts that in active worms, "the anterior end is simply turned sharply in the direction opposite to that in which it is when it receives the stimulus. . . . Thus it is turned toward the light about as often as from it, regardless of the light intensity." " Sluggish individuals, however, reacted quite differently.

${ }^{3}$ Torrey and Hays, 1914.

4 Light and the Behavior of Organisms. 1910, p. 200. 
From what we judge to have been a neutral position, six sluggish individuals, in one hundred and fifty trials, turned toward the light in but ten of them. In certain other cases there "was no evidence of even the slightest preliminary turning toward the source of light." (P. 201.)

From this evidence ours differs in that our active individuals behaved in the low intensities of light used very much like the sluggish individuals of Mast. Whatever the ultimate significance of this distinction, we have been forced to conclude, as Mast appears to have concluded, that under some conditions, earthworms respond to photic stimulation by orienting reactions that are in no sense trial or random movements. Nevertheless, in our figures, there was unmistakable evidence of that tendency which has been mentioned of the anterior end to swing from side to side This did not appear, however, in our first series of experiments.

In our first series, sixteen active individuals, taken from darkness, were each subjected to one hundred exposures in quick succession to a very low light intensity. The worm under observation crawled over a moist slate. When, in very weak diffused light, the anterior end was pointed straight forward, the light of a small pocket lamp was flashed upon it from a distance of $50 \mathrm{~mm}$. at an angle of ninety degrees with the body axis. The results are shown in the accompanying table.

From these figures it appears that our earthworms exhibited a marked disposition to react without trial negatively to the light used.

Our second series of observations was taken under somewhat different conditions, and shows very clearly the tendency to which we have alluded above Each of ten worms was subjected to a total of but thirty trials, in groups of ten. In the first ten trials, the anterior end was bent toward the light at the instant the light was flashed; in the second ten it was in a neutral position, that is, directed forward; in the third ten, it was bent away from the light. Each worm was rested for about seven minutes in darkness after each group of ten trials. A light of slightly greater intensity was used, namely, a $25 \mathrm{w}$. Mazda lamp, $160 \mathrm{~mm}$. distant, so screened that the ray falling on the worm was about $8 \mathrm{~mm}$. wide. In other respects, the conditions were essentially the same as in the first series 
TABLE 1

\begin{tabular}{|c|c|c|c|}
\hline & \multirow{2}{*}{$\begin{array}{l}\text { No. of } \\
\text { trials }\end{array}$} & \multicolumn{2}{|c|}{$\begin{array}{l}\text { Direction of first } \\
\text { movement }\end{array}$} \\
\hline & & $\begin{array}{c}\text { Toward } \\
\text { light }\end{array}$ & $\begin{array}{l}\text { Away from } \\
\text { light }\end{array}$ \\
\hline 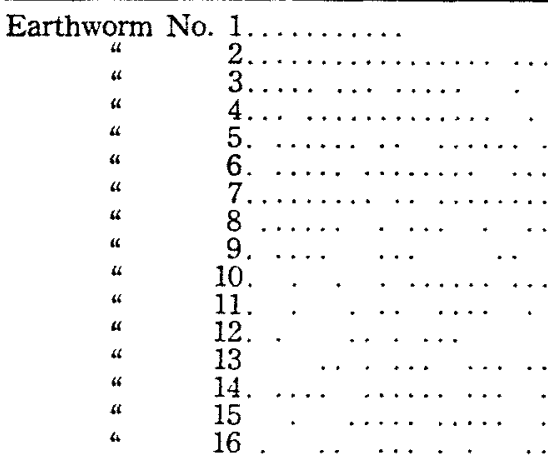 & $\begin{array}{l}100 \\
100 \\
100 \\
100 \\
100 \\
100 \\
100 \\
100 \\
100 \\
100 \\
100 \\
100 \\
100 \\
100 \\
100 \\
100\end{array}$ & $\begin{array}{l}18 \\
22 \\
18 \\
28 \\
16 \\
26 \\
34 \\
14 \\
24 \\
28 \\
12 \\
32 \\
20 \\
21 \\
43 \\
34\end{array}$ & $\begin{array}{l}82 \\
78 \\
82 \\
72 \\
84 \\
74 \\
66 \\
86 \\
76 \\
72 \\
88 \\
68 \\
80 \\
79 \\
57 \\
66\end{array}$ \\
\hline Totals . $\ldots \quad \ldots \quad \ldots \ldots$ & 1600 & 390 & 1210 \\
\hline Percentages...... . . & . & $244 \%$ & $756 \%$ \\
\hline
\end{tabular}

TABLE 2

\begin{tabular}{|c|c|c|c|c|c|c|c|}
\hline \multirow[b]{3}{*}{ Sense of response.. } & \multirow{3}{*}{$\begin{array}{l}\text { No. of } \\
\text { trials } \\
\ldots \ldots\end{array}$} & \multicolumn{6}{|c|}{$\begin{array}{c}\text { Position of anterior end with reference } \\
\text { to light }\end{array}$} \\
\hline & & \multicolumn{2}{|c|}{ Toward } & \multicolumn{2}{|c|}{ Neutral } & \multicolumn{2}{|c|}{ Away } \\
\hline & & - & + & 一 & + & 一 & + \\
\hline 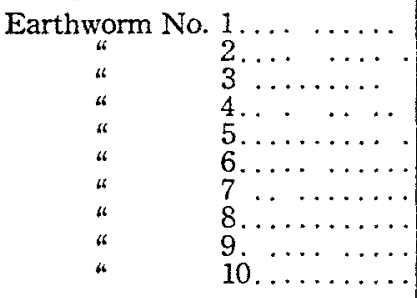 & $\begin{array}{l}30 \\
30 \\
30 \\
32 \\
30 \\
30 \\
30 \\
30 \\
30 \\
30\end{array}$ & $\begin{array}{r}9 \\
8 \\
8 \\
10 \\
10 \\
10 \\
10 \\
10 \\
10 \\
10\end{array}$ & $\begin{array}{l}1 \\
2 \\
2 \\
0 \\
0 \\
0 \\
0 \\
0 \\
0 \\
0\end{array}$ & $\begin{array}{r}8 \\
9 \\
9 \\
10 \\
9 \\
8 \\
8 \\
9 \\
8 \\
9\end{array}$ & $\begin{array}{l}2 \\
1 \\
1 \\
1 \\
1 \\
2 \\
2 \\
1 \\
2 \\
1\end{array}$ & $\begin{array}{r}9 \\
9 \\
7 \\
8 \\
7 \\
9 \\
8 \\
9 \\
10 \\
9\end{array}$ & $\begin{array}{l}1 \\
1 \\
3 \\
3 \\
3 \\
1 \\
2 \\
1 \\
0 \\
1\end{array}$ \\
\hline Totals. & 302 & 95 & 5 & 87 & 14 & 85 & 16 \\
\hline $\begin{array}{l}\text { Percentages of first movements } \\
\text { away from light........... }\end{array}$ & & $95 \%$ & & 86. & & 83. & \\
\hline
\end{tabular}


Assuming now, the observed tendency of the anterior end to swing in fairly regular alternation from side to side in successive extensions; and assuming, further, the tendency brought out by the figures just given, for the anterior end to swing directly away from the light; one should expect to find the anterior end swinging away from the light most frequently, in this second series, when it was turned toward the light at the instant the latter was flashed, and least frequently when it was turned away from the light at the moment of flashing

This expectation is, in fact, realized in the following figures. The light was flashed on the right of the first seven individuals, on the left of the others.

The third double column of figures is especially significant. as it shows a very marked negative reaction of the worms observed, under the conditions of the experiment, in spite of the conflicting tendency manifested in diffused light to swing the anterior end in the opposite direction.

Holmes has pointed out the danger of failing to notice certain very inconspicuous movements that might be started toutard the light but not followed up. We have tried to guard against this opportunity for error. At the same time, it may be worth while to remark that a certain degree of extension of the anterior segments appears to be necessary to expose the photoreceptors to effective light intensities Our figures seem to us to show clearly that photic stimulation, far from inducing random movements, immediately calls forth reactions in a definitely predictable direction. In the face of the facts, a view based upon minute random movements that are not referable to photic stimulation can hardly affect the conclusion that the earthworm must be placed, with Porccllo, in that group of organisms whose orientation to light is determined essentially by movements that are predictable as to direction and hence neither random movements nor "trials." 